\title{
Involuntary psychiatric hospitalisation, stigma stress and recovery: a 2-year study
}

\author{
Z. Xu' ${ }^{1}$, B. Lay $^{2}$, N. Oexle ${ }^{1}$, T. Drack ${ }^{2}$, M. Bleiker ${ }^{2}$, S. Lengler ${ }^{2}$, C. Blank ${ }^{2}$, M. Müller ${ }^{2}$, B. Mayer ${ }^{3}$, \\ W. Rössler ${ }^{2,4,5}$ and N. Rüsch ${ }^{1 *}$ \\ ${ }^{1}$ Department of Psychiatry II, University of Ulm and BKH Günzburg, Ulm, Germany \\ ${ }^{2}$ Department of Psychiatry, Psychotherapy and Psychosomatics, Zürich University Hospital of Psychiatry, Zurich, Switzerland \\ ${ }^{3}$ Institute of Epidemiology and Medical Biometry, University of Ulm, Ulm, Germany \\ ${ }^{4}$ Laboratory of Neuroscience, Institute of Psychiatry, LIM27, University of Sao Paulo, Sao Paulo, Brazil \\ ${ }^{5}$ Department of Psychiatry and Psychotherapy, Charité University Medicine, Berlin, Germany
}

\begin{abstract}
Aims. Compulsory admission can be experienced as devaluing and stigmatising by people with mental illness. Emotional reactions to involuntary hospitalisation and stigma-related stress may affect recovery, but longitudinal data are lacking. We, therefore, examined the impact of stigma-related emotional reactions and stigma stress on recovery over a 2-year period.
\end{abstract}

Method. Shame and self-contempt as emotional reactions to involuntary hospitalisation, stigma stress, self-stigma and empowerment, as well as recovery were assessed among 186 individuals with serious mental illness and a history of recent involuntary hospitalisation.

Results. More shame, self-contempt and stigma stress at baseline were correlated with increased self-stigma and reduced empowerment after 1 year. More stigma stress at baseline was associated with poor recovery after 2 years. In a longitudinal path analysis more stigma stress at baseline predicted poorer recovery after 2 years, mediated by decreased empowerment after 1 year, controlling for age, gender, symptoms and recovery at baseline.

Conclusion. Stigma stress may have a lasting detrimental effect on recovery among people with mental illness and a history of involuntary hospitalisation. Anti-stigma interventions that reduce stigma stress and programs that enhance empowerment could improve recovery. Future research should test the effect of such interventions on recovery.

Received 13 September 2017; Accepted 23 December 2017; First published online 31 January 2018

Key words: Coercion, compulsory admission, empowerment, stigma stress, recovery.

\section{Introduction}

Involuntary admissions to psychiatric hospitals are common but may have pernicious consequences for people with mental illness. Stigma refers to labelling, stereotyping, separation, status loss and discrimination that occur in a situation that gives relatively less power to the stigmatised (Link \& Phelan, 2001). This conceptualisation explains why compulsory hospitalisation may increase the likelihood that people with mental illness feel devalued and stigmatised, as compulsory admission involves the exercise of power in treating labelled individuals and may constitute a loss of social status (Link et al. 2008; Livingston \& Rossiter, 2011). Involuntarily admitted individuals may feel shame and be embarrassed as a reaction to having deviated

* Address for correspondence: N. Rüsch, Department of Psychiatry II, University of Ulm and BKH Günzburg, Parkstrasse 11, 89073 Ulm, Germany.

(Email: nicolas.ruesch@uni-ulm.de) from cultural or social norms (Gilbert \& Andrews, 1998; Svindseth et al. 2013). On the other hand, failure to meet one's own expectations may result in selfcontempt (Green et al. 2013; Zahn et al. 2015). It has been proposed that individuals are more likely to devalue themselves if they feel no control over their treatment and feel incapable of functioning independently (Katsakou \& Priebe, 2007). These stigma-related emotional reactions to involuntary hospitalisation can be stressful even after discharge (Katsakou et al. 2012; Rüsch et al. 2014b). According to stress-coping models of stigma (Lazarus \& Folkman, 1984; Major \& O'Brien, 2005), however, people with mental illness are not passive recipients of stigma and its negative consequences. Stigma-related stress occurs when individuals perceive a stigma-related threat that exceeds their perceived coping resources. Thus, stigma stress involves the primary cognitive appraisal of the harm resulting from stigma and the secondary appraisal of the resources the individual has to cope with that harm (Rüsch et al. 2009a, b). 
Self-stigma describes the cognitive process of agreeing with and internalising negative stereotypes ('Because I have a mental illness, I am worthless and can never get better'). It is associated with the emotions of shame (Rüsch et al. 2006) and self-contempt, described by stigma theorists (Goffman, 1963) and people with lived experience of mental illness (Lipfird, 2015) as a barrier to recovery. Personal empowerment represents a sense of power, control, activism and optimism, which is often conceptualised as the opposite of self-stigma. The potential for self-stigma and impaired empowerment to influence recovery is consistent with the 'why try' effect (Corrigan et al. 2009), which suggests that people who internalise negative stereotypes of mental illness may suffer reduced self-worth and believe they are unworthy or incapable of achieving life goals, resulting in poor recovery.

A review of qualitative studies concluded that compulsory treatment can lead to loss of power, low selfesteem and feelings of hopelessness (Katsakou \& Priebe, 2007). In a longitudinal quantitative study, perceived coercion had detrimental effects on perceived stigma, decreased self-esteem and poor quality of life (Link et al. 2008). A cross-sectional study (Rüsch et al. $2014 b$ ) of our sample at baseline found that stigma stress, shame and self-contempt were associated with more self-stigma and impaired empowerment which were related to poor self-esteem and quality of life. A small longitudinal study of individuals with mental illness who received compulsory community treatment reported that self-stigma at baseline was negatively correlated with baseline quality of life, however, self-stigma did not predict the quality of life after 1 year (Livingston et al. 2011).

Recovery from mental illness involves not only returning to the pre-illness level of functioning but also regaining self-determination and the development of a meaningful life (Andresen et al. 2010; Silverstein et al. 2008). For involuntarily admitted individuals, the path to recovery includes developing a positive sense of identity, building self-esteem as well as taking back control over their treatment and lives (Slade et al. 2014). It is of particular value to understand how stigma-related emotional and cognitive responses to involuntary hospitalisation affect recovery in this population. Building on the previous findings (Link et al. 2008; Livingston et al. 2011; Rüsch et al. 2014b), we developed a path model in which shame, selfcontempt and stigma stress would predict self-stigma and empowerment, which further predict recovery over a 2-year period.

The current study aimed to test the hypotheses that (i) higher levels of shame and self-contempt in reaction to involuntary hospitalisation as well as more stigma stress at baseline would predict poor recovery after
2 years; and (ii) increased self-stigma and decreased empowerment after 1 year would mediate this relationship, controlling for age, gender, symptoms and baseline recovery.

\section{Methods \\ Participants}

This study is part of a randomised-controlled trial (RCT) of an intervention including psychoeducation, crisis cards and preventive monitoring to reduce compulsory psychiatric admissions among people with serious mental illness in the Canton of Zürich, Switzerland. Consecutive users of inpatient mental health care in four psychiatric hospitals in the Canton of Zürich, Switzerland, were invited to participate in the project. Participants fulfilled the following inclusion criteria: (a) at least one involuntary psychiatric hospitalisation in the past 24 months, (b) aged between 18 and 65 years, (c) living in the Canton of Zürich, Switzerland, and (d) ability to provide written informed consent. Exclusion criteria were an organic mental disorder, mental retardation or insufficient German language skills. Participants were recruited between April 2010 and July 2012. Eligible inpatients were randomised to the intervention or treatment as usual. Details of study design, sample characteristics and recruitment are described elsewhere (Lay et al. 2012).

We defined completers as participants who provided data at baseline as well as 1- or 2-year follow-up. Data for our analyses were available from 186 participants at baseline, $152(82 \%)$ at 1-year and $141(76 \%)$ at 2 -year follow-up. The main reasons for dropout were participants not being contactable, providing incomplete data or deciding to discontinue the study (Lay et al. 2012). ICD-10 psychiatric diagnoses were recorded for each participant from medical records. The most common psychiatric diagnoses were affective disorders $(n=80,43 \%)$ and psychotic disorders $(n=50$, $27 \%)$. In the whole sample, 57 (31\%) had a comorbid substance-related disorder. The average duration of mental illness was 16 years $(S D=12.5$, range $0.5-49$ years).

\section{Measures}

Emotional reactions to involuntary hospitalisation were assessed by one item on shame ('I felt shame to receive involuntary psychiatric treatment') and one item on self-contempt ('I felt self-contempt to receive involuntary psychiatric treatment'), both rated from 1 (not at all) to 9 (extreme) (Rüsch et al. 2014b).

Stigma stress was assessed by the 8-item Stigma Stress Scale (Rüsch et al. 2009a, b), which includes 
two 4-item subscales, one on the primary appraisal of mental illness stigma as harmful (e.g. 'Prejudice against people with mental illness will have harmful or bad consequences for me'; Cronbach's alpha $=0.95$ at baseline) and the other on the secondary appraisal of perceived coping resources (e.g. 'I have the resources I need to handle problems posed by prejudice against people with mental illness'; Cronbach's alpha $=0.86$ at baseline). Items were scored from 1 to 7 with higher scores representing higher agreement. Stigma stress was computed by subtracting perceived coping resources from perceived harmfulness, higher difference scores from -6 to +6 indicating more stigma stress.

Self-stigma was measured by the 29-item Internalized Stigma of Mental Illness Inventory (ISMI, Ritsher et al. 2003). The ISMI is designed to assess internalised and subjective experience of stigma, which comprises five subscales: alienation, stereotype endorsement, discrimination experience, social withdrawal and stigma resistance. Since the 5-item stigma resistance subscale had low internal consistency in our sample (Cronbach's alpha $=0.54$ at baseline and at 1-year follow-up), it was not included in the total score. A mean score from 1 to 4 in the remaining 24 items was calculated. Higher scores indicate more selfstigma. The 28-item Empowerment Scale (Rogers et al. 1997) was used to assess the personal sense of empowerment with higher mean scores from 1 to 4 equaling greater empowerment (baseline/1-year follow-up: Cronbach's alpha =0.84/0.80).

Self-esteem was assessed using the 10-item Rosenberg Self-Esteem Scale (Rosenberg, 1965) with a mean score between 0 and 3 (Baseline/2-year follow-up: Cronbach's alpha $=0.88 / 0.89$ ). Overall functioning was assessed by the Global Assessment of Functioning (American Psychiatric Association, 2000) from 1 to 100. Self-esteem and functioning were positively correlated $(r=0.45, \quad p<0.001, \quad$ at 2 -year follow-up). Z-standardised scores of self-esteem and functioning were calculated and then averaged into one recovery score, by transforming the mean scores of the two scales into percentile scores. At baseline, all measures were administered. Data on self-stigma and empowerment were collected again at 1-year follow-up, recovery again at 2-year follow-up. Symptoms were assessed by the 24-item Brief Psychiatric Rating Scale (Lukoff et al. 1986) yielding sum scores at baseline, 1-year and 2-year follow-up.

\section{Statistical analyses}

Data were analysed using SPSS 21 and MPlus 7.4 (Muthén \& Muthén, 1998-2002). Independent t-test or Chi-square tests were used to compare baseline sociodemographic and clinical variables between completers and non-completers at 1- and 2-year follow-up. We used Pearson's correlations to analyse the associations between predictors (shame and self-contempt in reaction to involuntary hospitalisation and stigma stress, all at baseline), mediators (self-stigma and empowerment at 1-year follow-up) and outcome (recovery after 2 years).

The hypothesised model was then tested in a path analysis using Mplus and Maximum Likelihood estimation, controlling for age, gender, intervention status (intervention vs. control), symptoms and baseline levels of self-stigma, empowerment and recovery. In the path analysis, we examined whether stigma stress, shame and self-contempt in reaction to involuntary hospitalisation at baseline directly predicted recovery after 2 years. Additionally, the model tested mediation effects of self-stigma and empowerment at 1-year follow-up on the association between stigma stress, shame and selfcontempt in reaction to involuntary hospitalisation at baseline and recovery after 2 years. The model is considered to fit the data well when $\chi^{2} / \mathrm{df}<2, \mathrm{CFI}>0.90$, TLI $>$ 0.90, RMSEA $<0.08$, SRMR $<0.08$ (Kenny, 2015). Standardised coefficients and 95\% confidence intervals were based on 5000 bootstrapped standard errors.

We first tested the hypothesised model in Mplus and missing values were handled using Full Information Maximum Likelihood (FIML, Muthén \& Muthén 1998-2002). Since FIML does not handle missing values of covariates, we then used multiple imputations by Fully Conditional Specification as implemented in SPSS to impute missing values (White et al. 2011). Imputed data were based on observed values of all variables in the model including the covariate and outcome variables. The number of imputations was set to 5 . The hypothesised model was then tested in the imputed data.

\section{Results}

\section{Baseline characteristics of completers and non-completers}

The 34 individuals who did not participate in the 1-year follow-up assessment did not differ significantly from the 152 participants who completed it in terms of baseline sociodemographic or clinical characteristics, except for completers being older than noncompleters $(M=44.3$ vs. $M=38.0 ; t=2.9, p=0.004)$ and a higher dropout rate in the intervention group ( $65 \%$ vs. $44 \% ; \chi^{2}=4.7, p=0.03$ ). One difference in baseline characteristics between completers and noncompleters at 2-year follow-up was observed, namely completers being older than non-completers $(M=44.5$ vs. $M=38.9 ; t=2.8, p=0.005$; Table 1 ). 
Table 1. Comparison of completers and non-completers at baseline (total $\mathrm{n}=186$ )

\begin{tabular}{|c|c|c|c|c|c|c|c|c|}
\hline \multirow[t]{2}{*}{ Variables (Range of possible scores) } & \multicolumn{2}{|c|}{$\begin{array}{l}\text { All participants } \\
\qquad(n=186)\end{array}$} & \multicolumn{2}{|c|}{$\begin{array}{l}\text { Completers } \\
(n=141)\end{array}$} & \multicolumn{2}{|c|}{$\begin{array}{c}\text { Non-completers } \\
\qquad(n=45)\end{array}$} & \multicolumn{2}{|c|}{ Statistics ${ }^{\mathrm{a}}$} \\
\hline & Mean & SD & Mean & SD & Mean & SD & $T$ & $p$ \\
\hline Age in years & 43.14 & 11.65 & 48.49 & 11.43 & 38.91 & 11.41 & 2.8 & 0.005 \\
\hline Shame $^{\mathrm{b}}(1-9)$ & 4.96 & 3.06 & 4.83 & 3.02 & 5.36 & 3.16 & -1.0 & 0.31 \\
\hline Self-contempt $t^{c}(1-9)$ & 3.30 & 2.72 & 3.22 & 2.69 & 3.55 & 2.83 & -0.7 & 0.49 \\
\hline Stigma stress ${ }^{\mathrm{d}}(-6$ to +6$)$ & -1.95 & 2.92 & -2.06 & 2.85 & -1.60 & 3.15 & -0.9 & 0.36 \\
\hline Self-stigma ${ }^{\mathrm{e}}(1-4)$ & 1.91 & 0.61 & 1.89 & 0.59 & 2.00 & 0.65 & 1.2 & 0.23 \\
\hline Empowerment $^{\mathrm{f}}(1-4)$ & 2.92 & 0.37 & 2.93 & 0.36 & 2.89 & 0.38 & 0.8 & 0.45 \\
\hline Recovery $^{\mathrm{g}}$ & -0.001 & 0.77 & 0.02 & 0.74 & -0.07 & 0.86 & 0.6 & 0.52 \\
\hline Self-esteem (0-3) & 1.91 & 0.72 & 1.93 & 0.71 & 1.89 & 0.79 & 0.4 & 0.72 \\
\hline Functioning (1-100) & 40.06 & 10.78 & 40.35 & 10.77 & 39.16 & 10.88 & 0.6 & 0.52 \\
\hline Involuntary hospitalisation $^{\mathrm{h}}$ & 1.60 & 1.05 & 1.53 & 0.97 & 1.82 & 1.25 & -1.6 & 0.10 \\
\hline \multirow[t]{2}{*}{$\mathrm{BPRS}^{\mathrm{i}}(24-168)$} & 42.28 & 10.06 & 42.20 & 9.83 & 42.53 & 10.86 & -0.2 & 0.85 \\
\hline & $N$ & $\%$ & $N$ & $\%$ & $N$ & $\%$ & $\chi^{2}$ & $p$ \\
\hline Gender (male) & 78 & 42 & 59 & 42 & 19 & 42 & 0.002 & 0.96 \\
\hline Intervention (yes) & 89 & 48 & 63 & 45 & 26 & 58 & 2.4 & 0.13 \\
\hline Substance-related disorders (yes) & 80 & 43 & 61 & 43 & 19 & 42 & 0.2 & 0.90 \\
\hline Psychotic disorders (yes) & 50 & 27 & 37 & 26 & 13 & 29 & 0.1 & 0.73 \\
\hline Affective disorders (yes) & 80 & 43 & 65 & 46 & 15 & 33 & 2.3 & 0.13 \\
\hline
\end{tabular}

${ }^{a}$ Comparison between completers and non-completers.

${ }^{\mathrm{b}}$ I I felt shame to receive involuntary psychiatric treatment'.

'I felt self-contempt to receive involuntary psychiatric treatment'.

${ }^{\mathrm{d}}$ Stigma Stress Scale.

Internalised Stigma of Mental Illness Inventory (without stigma resistance subscale).

${ }^{\mathrm{f}}$ Empowerment Scale.

gZ-standardised score of the Rosenberg's Self-Esteem Scale and Global Assessment of Functioning.

${ }^{h}$ Number of involuntary hospitalisations in the past 24 months.

${ }^{\mathrm{i} B r i e f}$ Psychiatric Rating Scale.

\section{Bivariate correlations between predictors, mediators and outcome variables}

Higher levels of stigma stress, shame and self-contempt at baseline were associated with more self-stigma $(r=0.49$, $p<0.001 ; r=0.24, p=0.005 ; r=0.28, p=0.001$, respectively) and less empowerment after 1 year $(r=-0.34, p<0.001$; $r=-0.22, p=0.009 ; r=-0.26, p=0.002$, respectively). At 1-year follow-up, self-stigma and empowerment were significantly negatively correlated $(r=-0.65, p<0.001)$. More stigma stress at baseline was associated with poorer recovery after 2 years $(r=-0.27, p=0.003)$, whereas shame and self-contempt at baseline were unrelated to recovery at 2-year follow-up $(r=-0.14, p=0.12 ; r=-$ $0.11, p=0.22$, respectively). More self-stigma and less empowerment after 1 year were related to poor recovery after 2 years $(r=-0.47, p<0.001 ; r=-0.50, p<0.001$, respectively). A higher level of symptoms at baseline was associated with more self-stigma $(r=0.28, p=0.001)$ and less empowerment after 1 year $(r=-0.20, p=0.02)$.
The number of involuntary hospitalisations in the 24 months before baseline was not correlated with stigma stress $(r=0.03, p=0.66)$, shame $(r=0.04, p=0.63)$ and self-contempt $(r=0.02, p=0.83)$ at baseline, with selfstigma $(r=0.14, p=0.11)$ and empowerment $(r=0.007$, $p=0.94)$ at 1-year follow-up, or with recovery $(r=-0.05$, $p=0.60$ ) after 2 years (Table 2 )

\section{Path analysis of the hypothesised model}

The path analysis based on non-imputed data indicated good model fit $\left(\chi^{2}=17.67, \mathrm{df}=15, p=0.28, \chi^{2} /\right.$ $\mathrm{df}=1.18, \quad \mathrm{RMSEA}=0.037, \quad \mathrm{CFI}=0.988, \quad \mathrm{TLI}=0.971$, $S R M R=0.030$, Fig. 1). In this path model, shame and self-contempt at baseline had no significant direct or indirect effect on recovery at 2-year follow-up. There was a trend-level negative association between shame at baseline and empowerment after 1 year. Stigma stress at baseline had a significant effect on self- 


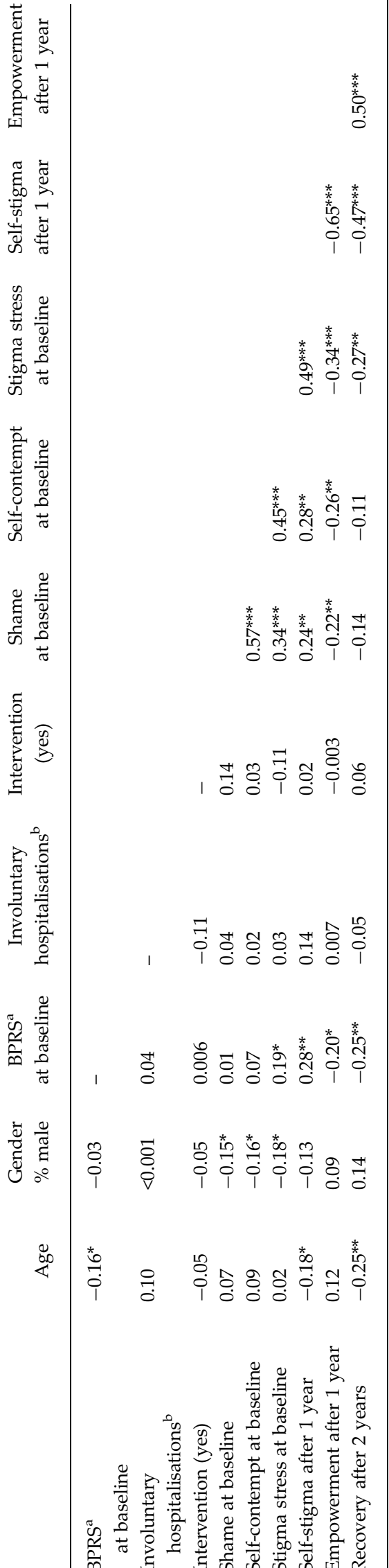

stigma and empowerment after 1 year. Empowerment at 1-year follow-up was significantly associated with recovery after 2 years. Stigma stress at baseline and recovery after 2 years were significantly associated in a bivariate correlation $(r=-0.27, p=0.003)$; in the full model, this association was not significant $r=0.02$, $p=0.82)$, suggesting full mediation. Decreased empowerment after 1 year fully mediated the link between baseline stigma stress and recovery after 2 years $(\beta=-0.05,95 \% \mathrm{CI}-0.13$ to -0.003$)$. More than half of recovery's variance was explained by the model $\left(R^{2}=0.57\right)$.

To account for a potential bias due to dropouts and missing data after 1 and 2 years, we repeated the path analysis following multiple imputations of missing data. The model fit of the path model in the imputed data was good $\left(\chi^{2}=27.19, \mathrm{df}=15, p=0.20, \chi^{2} / \mathrm{df}=\right.$ 1.82 , $\mathrm{RMSEA}=0.054, \mathrm{CFI}=0.971, \mathrm{TLI}=0.930, \mathrm{SRMR}=$ 0.029, Online Fig. S1). The results based on imputed data were almost identical to those based on nonimputed data.

\section{Discussion}

Our findings suggest that increased stigma stress had a long-term negative effect on recovery, mediated by decreased empowerment and independent of age, gender, symptom levels and baseline recovery. Consistent with previous findings (Rüsch et al. 2014b), shame, selfcontempt and stigma stress were correlated with increased self-stigma and decreased empowerment after 1 year. There was no significant correlation between the number of recent involuntary hospitalisations before baseline and self-stigma, empowerment or recovery, which indicates that the emotional and cognitive perceptions of coercion, rather than the coercive experiences per se, may determine the negative impact of involuntary hospitalisation. In the path analysis, stigma stress, or the perception of stigmatised individuals that they do not have sufficient resources to cope with stigma-related harm, is a more important determinant of self-stigma and impaired empowerment than shame and self-contempt, which is consistent with stress-coping models of mental illness stigma (Lazarus \& Folkman, 1984; Rüsch et al. 2009a, b).

The findings further confirm the concept of selfstigma and empowerment as opposite poles of a continuum (Rüsch et al. 2014b). At the negative end of the continuum are people who internalise negative stereotypes of mental illness and have low self-esteem and self-efficacy. At the positive end are people who have a sense of power and are confident about the pursuit of their goals (Corrigan et al. 2009). Our findings are also in line with studies that highlight the role of 


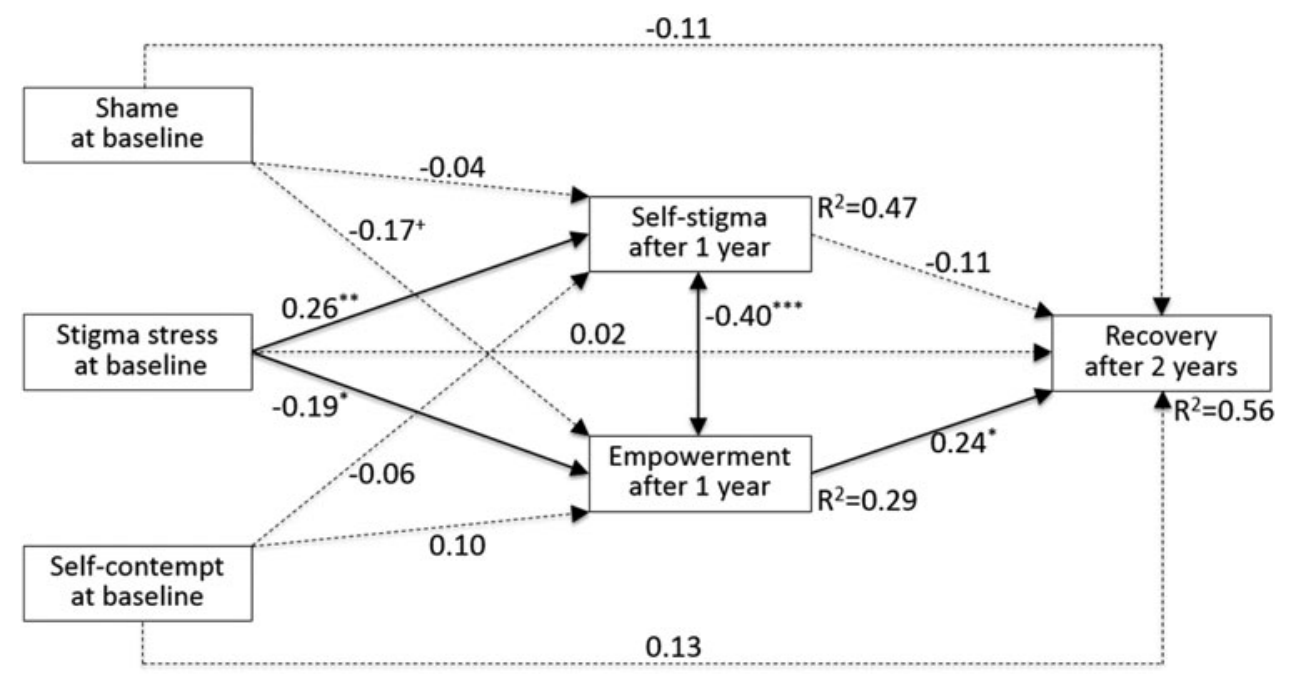

Fig. 1. Stigma stress and emotional reactions to involuntary hospitalisation as predictors of recovery after 2 years, controlling for baseline levels of all three dependent variables as well as for age, gender, symptoms and intervention status. Standardised path coefficients and Full Information Maximum Likelihood in Mplus $(n=131)$. For results of the same model with imputed data $(n=186)$ see Online Figure $1 .{ }^{*} p<0.05,{ }^{* *} p<0.01,{ }^{* * *} p<0.001,+p=0.08$.

empowerment for recovery from serious mental illness (Leamy et al. 2011). Empowering people with mental illness should be an important goal of interventions to achieve gains in social functioning and self-concept because socialisation and a functional sense of self-appear to be important factors involved in recovery (Silverstein et al. 2008). For example, individuals who have the confidence they can cope with stigma and its harmful consequences in the social context may have a sense of control and mastery that supports their recovery.

Although stigma stress in our study did not specifically refer to the stigma associated with involuntary hospitalisation, in a large international survey individuals with schizophrenia suffered from more experienced discrimination and thus were more likely to be distressed by it if they had experienced involuntary treatment (Thornicroft et al. 2009). Future research should include participants with and without a history of compulsory admission to examine whether our findings are specific for people with experience of involuntary treatment. That said, recent findings suggest that stigma stress negatively affects even individuals with subthreshold syndromes in the community (Schibalski et al. 2017). Future studies should also compare the role of mental health service systems and different compulsory admission rates for stigma's impact on recovery.

To the best of our knowledge, this is the first longitudinal study on stigma-related cognitive as well as emotional reactions to involuntary hospitalisation. Data collected at baseline, 1- and 2-year follow-up allow testing possible causal relationships between stigma-related variables and recovery in path analysis.
We also adjusted for several potential confounding variables in the path analysis. The findings add to our knowledge about long-term effects of stigma on recovery among people with severe mental illness.

This study has some limitations. Almost one-fourth of participants had dropped out after 2 years and noncompleters were younger than completers. The results based on imputed data were almost identical to those with non-imputed data, suggesting that dropout did not bias our findings. Recovery was not assessed by a comprehensive measure of personal recovery; instead, it was operationalised as the average of selfreported self-esteem and clinician-rated functioning, reflecting key domains of clinical and personal recovery. Other domains such as hope and optimism were not included and should be examined in future studies. Last not least, a longitudinal path analysis does not prove causality.

Despite these limitations, our findings have implications for efforts to reduce stigma's impact and to support recovery. In this study, randomisation to the intervention condition, which included psychoeducation, crisis cards and preventive monitoring, was controlled for in path analyses. It was not associated with improvement in selfstigma, empowerment or recovery, which underlines that additional and targeted interventions may be needed to reduce the negative impact of involuntary hospitalisation in the long-term. Given the path from stigma stress via disempowerment to poor recovery, there are two promising targets for interventions. Firstly, besides different interventions to reduce self-stigma among people with mental illness (Mittal et al. 2012; Tsang et al. 2016), the peer-led Honest, Open, Proud group program 
(HOP, formerly known as Coming Out Proud) empowers individuals to make decisions, whether or not to disclose their mental illness in different settings. In three RCTs (Rüsch et al. 2014a; Corrigan et al. 2015; Mulfinger et al. 2018) HOP significantly reduced stigma stress. The acquired decision-making skills might be continually used by participants after the intervention, which could improve resilience to stigma and reduce stigma-related stress. Based on our path model, we could speculate that HOP, by reducing stigma stress as a proximal outcome, might support long-term recovery as a distal outcome. Secondly, interventions that directly promote empowerment, such as advance directives or joint crisis plans, may foster recovery. As a recovery-oriented intervention, advance directives could empower individuals through the enhancement of insight, self-esteem, control over and satisfaction with treatment (Khazaal et al. 2014). Joint crisis plans support the empowerment process while facilitating early detection and relapse prevention (Henderson et al. 2015).

Future studies should examine whether recovery can be improved by interventions that address public stigma among key groups such as healthcare providers or police; that reduce compulsion rates and their negative effects in healthcare systems (de Jong et al. 2016); and that support individuals with mental illness in their struggle with self-stigma and stigma stress and in their effort to gain empowerment.

\section{Supplementary material}

The supplementary material for this article can be found at https://doi.org/10.1017/S2045796018000021.

\section{Acknowledgements}

We are grateful to all participants.

\section{Financial Support}

This study was supported by the Zürich Program for Sustainable Development of Mental Health Services (www.zinep.ch).

\section{Conflict of Interest}

None.

\section{Ethical Standards}

All participants gave their written informed consent. The study was approved by the regional ethics committee of Zürich, Switzerland.

\section{Availability of Data and Materials}

Participants provided written informed consent under the condition of confidentiality of their data. Therefore, data cannot be shared publicly.

\section{References}

American Psychiatric Association (2000). Diagnostic and Statistical Manual of Mental Disorders: DSM-IV-TR. American Psychiatric Association: Washington, DC.

Andresen R, Caputi P, Oades LG (2010). Do clinical outcome measures assess consumer-defined recovery? Psychiatry Research 177, 309-317.

Corrigan PW, Larson J, Michaels P, Buchholz B, Del Rossi R, Fontecchio M, Castro D, Gause M, Krzyzanowski R, Rüsch $\mathbf{N}$ (2015). Diminishing the self-stigma of mental illness by coming out proud. Psychiatry Research 229, 148-154.

Corrigan PW, Larson JE, Rüsch N (2009). Self-stigma and the "why try" effect: impact on life goals and evidence-based practices. World Psychiatry 8, 75-81.

de Jong MH, Kamperman AM, Oorschot M, Priebe S, Bramer W, van de Sande R, Van Gool AR, Mulder CL (2016). Interventions to reduce compulsory psychiatric admissions: a systematic review and meta-analysis. JAMA Psychiatry 73, 657-664.

Gilbert P, Andrews B (1998). What is shame? Some core issues and controversies. In Gilbert P, Andrews B (eds) Shame: Interpersonal Behavior, Psychopathology, and Culture. Oxford University Press: New York; 1998, pp. 3-38.

Goffman E (1963). Notes on the Management of Spoiled Identity. Simon \& Schuster: New York.

Green S, Moll J, Deakin JF, Hulleman J, Zahn R (2013). Proneness to decreased negative emotions in major depressive disorder when blaming others rather than oneself. Psychopathology 46, 34-44.

Henderson C, Farrelly S, Moran P, Borschmann R, Thornicroft G, Birchwood $M$, the Crimson and Joshua Study Groups (2015). Joint crisis planning in mental health care: the challenge of implementation in randomized trials and in routine care. World Psychiatry 14, 281-283.

Katsakou C, Priebe S (2007). Patient's experiences of involuntary hospital admission and treatment: a review of qualitative studies. Epidemiologia e Psichiatria Sociale 16, 172-178.

Katsakou C, Rose D, Amos T, Bowers L, McCabe R, Oliver D, Wykes T, Priebe S (2012). Psychiatric patients' views on why their involuntary hospitalisation was right or wrong: a qualitative study. Social Psychiatry and Psychiatric Epidemiology 47, 1169-1179.

Kenny D (2015). SEM: Measuring Model Fit. http:// davidakenny.net/cm/fit.htm.

Khazaal Y, Manghi R, Delahaye M, Machado A, Penzenstadler L, Molodynski A (2014). Psychiatric advance directives, a possible way to overcome coercion and promote empowerment. Front Public Health 2, 37.

Lay B, Salize HJ, Dressing H, Rüsch N, Schönenberger T, Bühlmann M, Bleiker M, Lengler S, Korinth L, Rössler W (2012). Preventing compulsory admission to psychiatric 
inpatient care through psycho-education and crisis focused monitoring. BMC Psychiatry 12, 136.

Lazarus R, Folkman S (1984). Stress, Appraisal, and Coping. Springer: New York.

Leamy M, Bird V, Le Boutillier C, Williams J, Slade M (2011). Conceptual framework for personal recovery in mental health: systematic review and narrative synthesis. British Journal of Psychiatry 199, 445-452.

Link B, Castille DM, Stuber J (2008). Stigma and coercion in the context of outpatient treatment for people with mental illnesses. Social Science \& Medicine 67, 409-419.

Link BG, Phelan JC (2001). Conceptualizing stigma. Annual Review of Sociology 27, 363-385.

Lipfird AC (2015). Self-stigma: a personal journey. Psychiatric Rehabilitation Journal 38, 201-202.

Livingston JD, Rossiter KR (2011). Stigma as perceived and experienced by people with mental illness who receive compulsory community treatment. Stigma Research and Action 1, 1-8.

Livingston JD, Rossiter KR, Verdun-Jones SN (2011). 'Forensic' labelling: an empirical assessment of its effects on self-stigma for people with severe mental illness. Psychiatry Research 188, 115-122.

Lukoff D, Liberman RP, Nuechterlein KH (1986). Symptom monitoring in the rehabilitation of schizophrenic patients. Schizophrenia Bulletin 12, 578.

Major B, O'Brien LT (2005). The social psychology of stigma. Annual Review of Psychology 56, 393-421.

Mittal D, Sullivan G, Chekuri L, Allee E, Corrigan PW (2012). Empirical studies of self-stigma reduction strategies: a critical review of the literature. Psychiatric Services 63, 974-981.

Mulfinger N, Müller S, Böge I, Sakar V, Corrigan PW, Evans-Lacko S, Nehf L, Djamali J, Samarelli A, Kempter M, Ruckes C, Libal G, Oexle N, Noterdaeme M, Rüsch N (2018). Honest, Open, Proud for adolescents with mental illness: pilot randomized controlled trial. Journal of Child Psychology and Psychiatry doi: 10.1111/jcpp.12853.

Muthén L, Muthén B (1998-2002). Mplus User's Guide, 7th edn. Muthén \& Muthén: Los Angeles, CA.

Ritsher JB, Otilingam PG, Grajales M (2003). Internalized stigma of mental illness: psychometric properties of a new measure. Psychiatry Research 121, 31-49.

Rogers ES, Chamberlin J, Ellison ML, Crean T (1997). A consumer-constructed scale to measure empowerment among users of mental health services. Psychiatric Services 48, 1042-1047.

Rosenberg M (1965). Society and the Adolescent Self-Image. Princeton University Press: Princeton.

Rüsch N, Abbruzzese E, Hagedorn E, Hartenhauer D, Kaufmann I, Curschellas J, Ventling S, Zuaboni G, Bridler R, Olschewski M, Kawohl W, Rössler W, Kleim B, Corrigan PW (2014a). Efficacy of coming out proud to reduce stigma's impact among people with mental illness: pilot randomised controlled trial. British Journal of Psychiatry 204, 391-397.

Rüsch N, Corrigan PW, Powell K, Rajah A, Olschewski M, Wilkniss S, Batia K (2009b). A stress-coping model of mental illness stigma: II. Emotional stress responses, coping behavior and outcome. Schizophrenia Research 110, 65-71.

Rüsch N, Corrigan PW, Wassel A, Michaels P, Olschewski M, Wilkniss S, Batia K (2009a). A stress-coping model of mental illness stigma: I. Predictors of cognitive stress appraisal. Schizophrenia Research 110, 59-64.

Rüsch N, Hölzer A, Hermann C, Schramm E, Jacob GA, Bohus M, Lieb K, Corrigan PW (2006). Self-stigma in women with borderline personality disorder and women with social phobia. Journal of Nervous and Mental Disease 194, 766-773.

Rüsch N, Müller M, Lay B, Corrigan PW, Zahn R, Schönenberger T, Bleiker M, Lengler S, Blank C, Rössler W (2014b). Emotional reactions to involuntary psychiatric hospitalization and stigma-related stress among people with mental illness. European Archives of Psychiatry and Clinical Neurosciences 264, 35-43.

Schibalski JV, Müller M, Ajdacic-Gross V, Vetter S, Rodgers S, Oexle N, Corrigan PW, Rössler W, Rüsch N (2017).

Stigma-related stress, shame and avoidant coping reactions among members of the general population with elevated symptom levels. Comprehensive Psychiatry 74, 224-230.

Silverstein SM, Bellack AS (2008). A scientific agenda for the concept of recovery as it applies to schizophrenia. Clinical Psychology Review 28, 1108-1124.

Slade M, Amering M, Farkas M, Hamilton B, O'Hagan M, Panther G, Perkins R, Shepherd G, Tse S, Whitley R (2014). Uses and abuses of recovery: implementing recovery-oriented practices in mental health systems. World Psychiatry 13, 12-20.

Svindseth MF, Nottestad JA, Dahl AA (2013). Perceived humiliation during admission to a psychiatric emergency service and its relation to socio-demography and psychopathology. BMC Psychiatry 13, 217.

Thornicroft G, Brohan E, Rose D, Sartorius N, Leese M (2009). Global pattern of experienced and anticipated discrimination against people with schizophrenia: a cross-sectional survey. Lancet 373, 408-415.

Tsang HW, Ching SC, Tang KH, Lam HT, Law PY, Wan CN (2016). Therapeutic intervention for internalized stigma of severe mental illness: a systematic review and meta-analysis. Schizophrenia Research 173, 45-53.

White IR, Royston P, Wood AM (2011). Multiple imputation using chained equations: issues and guidance for practice. Statistics in Medicine 30, 377-399.

Zahn R, Lythe KE, Gethin JA, Green S, Deakin JF, Young AH, Moll J (2015). The role of self-blame and worthlessness in the psychopathology of major depressive disorder. Journal of Affective Disorders 186, 337-341. 